\title{
Agronomic Characters and Chemical composition of Sri Lankan Novel Red Pericarp Rice (Oryza sativa L.) Variety
}

\author{
Pitipana Achchige Nadini Thushara, Pahan Indika Godakumbura*, M. A. B \\ Prashantha
}

Department of Chemistry, Faculty of Applied Sciences, University of Sri Jayewardenepura, Nugegoda 10250, Sri Lanka

\begin{abstract}
Sri Lanka is a rich treasurable land of traditional rice cultivation and rice is the primary staple food in Sri Lanka. There are many unpopular rice varieties which have been derived from traditional rice varieties and their nutritional values are under investigation. One such novelSri Lankan red pericarp rice variety known as Gurupiya is focused on this study. Agronomic characters of novel rice variety was evaluated according to IRRI 1998. Standard methods of AOAC nutritional guidelines were used to obtain the proximate composition of Gurupiya rice variety (GPRV). AOCS methods were used to analyze oil profile. Fatty acid profile was determined by using GCMS. The results showed that crude protein, crude fiber, crude fat and carbohydrate contents were $12.0 \pm 0.1 \%, 1.5 \pm 0.1 \%, 2.6 \pm 0.4 \%, 75.9 \pm 0.1 \%$ respectively. Calorie content was $375.0 \mathrm{kcal} / 100 \mathrm{~g}$. According to the results, GPRV have high Zn content $(4.82 \mathrm{mg} / 100 \mathrm{~g})$. Fatty acid composition of the GPRV revealed that more than half of the total fatty acids were made up of unsaturated fatty acids (USFA) which are considered as important for good health. Results showed that iodine value (IV), acid value (AV), saponification value (SV) and peroxide value (PV) of GPRV were $72.1 \pm 3.5 \mathrm{~g} \mathrm{I} / 100 \mathrm{~g}, 21.4 \pm 2.7 \mathrm{mg} \mathrm{KOH} / \mathrm{g}, 202.13 \pm 2.5 \mathrm{mg}$ $\mathrm{KOH} / \mathrm{g}$ and $18.6 \pm 1.1 \mathrm{meq} \mathrm{O}_{2} / \mathrm{kg}$, respectively. The results reveal that novel GPRV shows high nutritional values than that of reported for the improved rice varieties. Therefore, consumption of GPRV will aid in the improvement of health condition.
\end{abstract}

Keywords — Traditional rice, proximate, fatty acid, oil, minerals.

\section{INTRODUCTION}

Rice is the major staple food in Sri Lanka. It is available in over 5000 varieties all over the world [1]. In ancient times, about 2000 conserved different traditional rice varieties known to have existed in Sri Lanka[2]. Within last few years, traditional rice is gradually making an increment of consumption mainly due to the global awareness on the benefits of consuming organic foods and the drawbacks of using chemical fertilizers and pesticides. The specialties of Sri Lankan traditional rice varieties can be highlighted as high nutritional value, different texture, appearance, aroma and taste compared to that of improved rice varieties[2]. The major nutrients of carbohydrate $(32.1 \mathrm{~g} / 100 \mathrm{~g}$ grain), protein $(2.6 \mathrm{~g} / 100 \mathrm{~g}$ grain), fat $(1.1 \mathrm{~g} / 100 \mathrm{~g}$ grain), and fiber $(0.8 \mathrm{~g} / 100 \mathrm{~g}$ grain $)$ are consisted in the rice grain and its bran [3]. Health benefits of rice are mainly due to the activities of phytochemicals such as phenolic compounds. Sri Lankan traditional rice varieties of Kaluheenati $(\mathrm{KH})$, Pokkali (PK), Gurusinghe wee (GW), Kahawanu (KW),
Sudumurunga(SM) and Unakola samba (US) provide high nutritional value which is free from heavy metals compared to improved rice [4]. Both parboiled and unparboiled Pokkali rice variety has been proven that it is a good dietary supplement for iron deficiency and for pregnant mothers due to the significantly high iron content [5]. Studies on Sri Lankan traditional and improved rice varieties have shown medium to high amylose content (5773). The high amylose content of traditional rice varieties corresponds to the lower glycemic index (GI) values and it resulted in decreased insulin responses [6,7]. Among them Wedaheenati rice exhibited the low GI (57) while the highest GI was reported in improved Bg 406 variety (73) [8]. Quite a few studies have linked GI with not only the rice but also the rice products such as porridges, curries and cereal products. Parboiled rice with Amaranthus leaf curry was classified as low GI (47) meal [9] while plain white rice have reported a relatively higher GI value (5092) [10]. Some parboiled varieties of traditional red rice as well as $\mathrm{Bg} 350$ improved variety have the low GI values 
(56-73) compared to some of the un-parboiled red rice and white rice. Research findings have highlighted that red parboiled varieties of rice and $\mathrm{Bg} 350$ can be recommended for patients with diabetes[11]. Previous studies have been provided evidence that the brans of Sri Lankan traditional rice varieties of Masuran, Dik Wee, GodaHeeneti and Sudu Heeneti have great antioxidant properties as well as oxidative stress associated chronic diseases can be prevented by consuming these rice [12]. In vitroglycation reversing and anti-glycation activity of Sri Lankan rice bran of 23 traditional as well as 12 improved (both red and white) rice varieties have been evaluated. Significantly high antiamylase and anti-glycation activities were observed for bran extracts of traditional red rice varieties, Masuran, Sudu Heeneti, Dik Wee and GodaHeeneti, compared to that of improved red rice varieties[13].One of the most important investigations illustrated the potential anti- cancer activity of rice bran of four Sri Lankan traditional varieties (GodaHeeneti, Sudu Heeneti, Dik Wee and Sudu Heeneti) against human lung cancer (NCI-H460) and cervical cancer (HeLa) cell lines. From the point of view of growth inhibition and cytotoxicity, it is becoming apparent that some of the Sri Lankan traditional rice varieties possess promising ability for management of cancer [14].

Therefore, studying the chemical compositions of the novel rice which has never seen before in the national collection of farmers has become a timely need for finding solutions in ways to overcome malnutrition and health problems. The main objective of this study was to determination of agronomic characteristics and chemical parameters (nutritional values, minerals, fatty-acid profile and rice oil) of novel rice variety "Gurupiya" which is known to be derived from traditional rice.

\section{MATERIALS AND METHODS}

\subsection{Determination of agronomic parameters}

The agronomic parameters were determined according to the method of Standard Evaluation System for Rice[15]. Plants which have grown in "Yala" season were taken in to account. Plant height $(\mathrm{cm})$, leaf blade length $(\mathrm{cm})$, leaf blade width $(\mathrm{cm})$, number of tillers per plant, number of internodes per plant, panicle length $(\mathrm{cm}), 100$ grain weight $(\mathrm{g})$, seed length $(\mathrm{mm})$ and seed width $(\mathrm{mm})$ were evaluated in this study. The previously reported traditional rice variety, KaluHeenati was used as the reference recommended rice cultivar for analyzing the agronomic parameters. [16]

\subsection{Determination of chemical parameters}

\subsubsection{Preparation of rice samples}

Raw paddy was de hulled (Satake THU 35B), ground and passed through a $500 \mu \mathrm{m}$ sieve to obtain a homogeneous fine powder. Freshly prepared samples were used to analyze chemical parameters.

\subsubsection{Proximate analysis}

Uniform fractions of rice flour were used to analyze moisture, protein $(\% \mathrm{~N} \times 6.25)$, fat, ash, fiber and carbohydrate by the methods of AOAC (2002).

\subsubsection{Calorie content}

Calorie content (kcal/ $100 \mathrm{~g}$ ) was calculated by use of specific energy factors of 4:9:4 for proteins, fat and carbohydrates, respectively.

\subsubsection{Analysis of Minerals}

An amount of $5.0 \mathrm{~g}$ of the ground rice sample was taken to a crucible and ashing procedure was carried out at $550^{\circ} \mathrm{C}$ in a muffle furnace $(n=3)$. Then, about 10 drops of conc. Hydrochloric acid were added to the ashed sample and mixed well. It was filtered into a $250 \mathrm{ml}$ volumetric flask and was topped up to the mark using distilled water. The final solution was used to analyze minerals (K, Na, Zn, Fe) using atomic absorption spectrometry (Thermo scientific, iCE3000 Series AAS).

\subsubsection{Analysis of fatty acid profile}

Fatty Acid Methyl Esters (FAMEs) were prepared by according to the ISO 5509-1978 (E) method. Then FAMEs were identified on GC model-7890 A, Agilent technologies equipped with Mass Spectrometer (MS) model-5975 C inert XL EI/CI MSD with triple-axis detector.

\subsubsection{Analysis of rice oil}

Saponification value was determined according to the A. O. C. S. Official Method Cd 3-25, 1999. Iodine value was determined (Wijs method) in accordance to the A. O. C. S. Official Method Cd 1-25, 1999. Peroxide value was determined according to the A. O. C. S. Official Method, $\mathrm{Cd} 8 \mathrm{~b}, 1999$. Acid value was determined according to the A. O. C. S. Official Method, Cd 3a-63, 1999.

\section{RESULTS AND DISCUSSION}

\subsection{Determination of agronomic parameters}

The average results of the measured agronomic parameters are given in the table 01. Age of the plants was 90 days when measuring the agronomic parameters.

Table.1. Average values of each trait of Gurupiya rice cultivar

\begin{tabular}{|l|l|}
\hline Plant height $(\mathrm{cm})$ & $110.4 \pm 0.7$ \\
\hline Leaf blade length $(\mathrm{cm})$ & $50.2 \pm 0.3$ \\
\hline Leaf blade width $(\mathrm{cm})$ & $1.2 \pm 0.03$ \\
\hline
\end{tabular}




\begin{tabular}{|l|l|}
\hline Number of tillers per plant & 4 \\
\hline Number of internodes per plant & 4 \\
\hline Panicle length $(\mathrm{cm})$ & $21.8 \pm 0.2$ \\
\hline Seed length $(\mathrm{mm})$ & $8.0 \pm 0.1$ \\
\hline Seed width $(\mathrm{mm})$ & $3.2 \pm 0.04$ \\
\hline 100 grain weight $(\mathrm{g})$ (before de hulled) & $3.1 \pm 0.03$ \\
\hline
\end{tabular}

The novel GPRV has red color pericarp. The weight of 100 seeds of GPRV was $3.1 \pm 0.03 \mathrm{~g}$. The highest value for 100 seeds weight was recorded for Galpawee $(3.10 \mathrm{~g})$ and the lowest value recorded for that was Mahasudu wee $(1.25 \mathrm{~g})$. A well-known traditional rice variety, KaluHeenati was selected as a reference rice cultivar throughout this study and it has the weight of $2.33 \mathrm{~g} / 100$ seeds. The average seed length of GPRV was $8.0 \pm 0.1 \mathrm{~mm}$ and the average seed width was $3.2 \pm 0.04 \mathrm{~mm}$. These values were in the similar range of KaluHeenati, which were $8.15 \mathrm{~mm}$ long and $2.86 \mathrm{~mm}$ width. The longest length of seeds was found in the Thanthiribalan $(9.12 \mathrm{~mm})$ and the shortest was in the Hathiel variety $(5.26 \mathrm{~mm})$. The highest seed width of $3.53 \mathrm{~mm}$ was reported for cultivar Podihatatha and the lowest seed width of $2.26 \mathrm{~mm}$ was recorded for Rathran wee [16]. According to the previous studies, about $65 \%$ of the evaluated traditional rice cultivars had reported the average plant heights in the range of $60 \mathrm{~cm}-100 \mathrm{~cm}$. The tallest rice cultivar, Podihatatha reported the height of $198 \mathrm{~cm}$ while KaluHeenati reported $86.8 \mathrm{~cm}$ of height[16]. Furthermore, the leaf blade length of GPRV showed in between value of $50.2 \pm 0.3 \mathrm{~cm}$ while Podihatatha rice cultivar was reported to have the highest value of $94.2 \mathrm{~cm}$ and KaluHeenati displayed as $40.9 \mathrm{~cm}$. The lowest leaf blade length was found in Hatheil rice cultivar of $8.7 \mathrm{~cm} \mathrm{[16].} \mathrm{Moreover,}$ the leaf blade width of GPRV $(1.2 \mathrm{~cm})$ is higher than that of Kaluheenai $(0.9 \mathrm{~cm})$. Kotanavalu cultivar had the broadest leaf blade width of $1.6 \mathrm{~cm}$, whereas Mahakuruwee had the narrowest leaf blade of $0.6 \mathrm{~cm}$. According to the results, GPRV has produced 4 tillers per plant and that value is higher than the tillers per KaluHeenati plant, which was the value of 2.6. Previous research has indicated that $55 \%$ of the rice cultivars produced less than 5 tillers per plant among the evaluated twenty cultivars [16]. Particularly, the panicle length of GPRV $(21.8 \pm 0.02 \mathrm{~cm})$ is in close agreement with that of KaluHeenati, which is $21.5 \mathrm{~cm}$. The longest panicle length was reported by Kahata wee $(29 \mathrm{~cm})$ where the shortest panicle was found in Rathran wee $(15.1 \mathrm{~cm})$ [16].

\subsection{Determination of chemical parameters}

The current study found that moisture content of novel rice variety GPRV was $7.5 \pm 0.1 \%$ and this value demonstrated the low moisture content compared to the other reported values for traditional rice varieties [4]. In a study which set out to determine proximate composition of rice, it was revealed that both Pokkali and Unakola Samba equally possess the high amount of moisture (11.9\%) content [4].This low amount of moisture content of GPRV suggests the high capacity of storage period of Gurupiya cultivar. The crude protein content of GPRV was $12.0 \pm 0.1$ $\%$, which indicates the higher amount of protein content compared to the previously studied six traditional rice varieties and improved varieties. Reported protein contents of Kaluheenati, Pokkali, Gurusinghe wee, Kahawanu, Sudumurunga and Unakola samba were in the range of $9.7 \pm 0.3 \%-11.0 \pm 0.4 \%$ [4], whereas improved $\mathrm{Bg}$ rice varieties were in the range of $6 \%-11 \%$.[17] However, studies have found that significant differences between plant and animal protein sources, mostly with cereal proteins such as rice because of their low lysine content.[18]A number of studies have shown the benefits of plant proteins over animal proteins for lowering blood pressure[19] and risk of type 2 diabates[20]. Therefore, this novel GPRV is a good source of plant protein which corresponds to health benefits. The crude fat content of the GPRV was $2.6 \pm 0.4 \%$ which is similar to the value of KaluHeenati.[4] Studies on chemical parameters of six traditional rice varieties have reported that their fat content was in the range of $2.3 \%-2.9 \%$.[4] Crude fiber content and ash content of GPRV was significantly high $(1.5 \pm 0.1$ $\%$ and $2.0 \pm 0.03 \%$ respectively) compared to that of previously reported traditional rice.[4] High fiber content of diet leads to several health benefits such as reducing gastrointestinal disorders including gastroesophageal reflux disease, duodenal ulcer, diverticulitis, constipation and hemorrhoids.[21] The total carbohydrate content of GPRV was calculated using reduction method and lies in the range of $75.9 \pm 0.1 \%$. This study proves that novel rice variety shows higher percentages of proteins, fat, fiber, ash and lower percentages of carbohydrates compared to widely consumed improved rice varieties in Sri Lanka.[22] Caloric value of GPRV was $375.0 \mathrm{Kcal} / 100 \mathrm{~g}$. Calorie contents of previously reported traditional rice varieties were in the range of $352.3-372.8 \mathrm{Kcal} / 100 \mathrm{~g}$. Among those values $372.8 \mathrm{Kcal} / 100 \mathrm{~g}$ was reported for KaluHeenati.[4] This high energy value of GPRV implies its high value to the body as a fuel for metabolic processes.

According to the mineral analysis, GPRV possess high amount of $\mathrm{Zn}(4.8 \pm 0.5 \mathrm{mg} / 100 \mathrm{~g})$ compared to the previously reported data [5]. GPRV is a good solution as a diet with high $\mathrm{Zn}$ content for people having zinc deficiency because studies have found that about $25 \%$ of the world's population is at risk of zinc deficiency.[23] The $\mathrm{Na}$ content and $\mathrm{K}$ content of the GPRV were $8.2 \pm 0.5$ $\mathrm{mg} / 100 \mathrm{~g}$ and $5.4 \pm 0.4 \mathrm{mg} / 100 \mathrm{~g}$ respectively. 
Fatty acid composition of the rice varieties depend on the genotype, seed maturity, climatic condition, growth and interaction between these factors [24]. The fatty acid profile of GPRV is presented in Table 2.

Table.2. Fatty acid profile of GPRV

\begin{tabular}{|l|l|l|l|l|l|l|l|l|}
\hline \multicolumn{1}{|c|}{ Fatty Acids } \\
\hline $16: 0$ & $16: 1 \mathrm{n}-7$ & $18: 0$ & $18: 1 \mathrm{n}-9$ & $20: 0$ & $20: 1 \mathrm{n}-7$ & $22: 0$ & $24: 0$ & $26: 0$ \\
\hline $20.0 \pm 0.2$ & $0.75 \pm 0.1$ & $4.77 \pm 0.2$ & $63.55 \pm 0.1$ & $2.75 \pm 0.1$ & $2.46 \pm 0.1$ & $2.85 \pm 0.2$ & $1.28 \pm 0.1$ & $1.50 \pm 0.1$ \\
\hline
\end{tabular}

*Expressed as \% of total fatty acids

The most prominent fatty acid is oleic acid (18:1n-9) and second highest is palmitic acid (16:0) presented in this GPRV. The percentage of total unsaturated fatty acids (USFA) in the GPRV was $66.75 \pm 0.2 \%$. It indicates that more than half of the total fatty acids were made up of USFA which are considered as important for good health. Oleic acid is considered as an essential fatty acid required for human growth and development and must be obtained from the diet and it is included in GPRV as the highest abundant fatty acid $(63.55 \%)$. Value of the USFA (unsaturated fatty acid) /SFA (saturated fatty acid) ratio was high (2.01). Therefore the GPRV is healthy and safe as manifested in the results. Further, higher contents of monounsaturated fatty acids including oleic acid enhance the stability of oil during cooking [25]. With regards to the current recommendations, there is a requirement of increasing the consumption of USFA and decrease intake of saturated fatty acids, in order to reduce cardiovascular disease risk. Hence, this novel red pericarp GPRV can be recommended as a good source of USFA.

The results of different chemical parameters of rice oil were obtained. These values are in close agreement with those reported in literature for two traditional rice varieties, Rathusooduru and Madathawalu[26]. Iodine value (IV) of GPRV was $72.1 \pm 3.5 \mathrm{~g} \mathrm{I} 2 / 100 \mathrm{~g}$. According to Codex standards (1999) the recommended range for refined rice oil is of 90-105 $\mathrm{g} \mathrm{I}_{2} / 100 \mathrm{~g}$. Acid value (AV) is used as an indicator for edibility and suitability for use in industry [27]. According to Codex Alimentarius Commission, AV for crude ice bran oil should be below 50 $\mathrm{mg} \mathrm{KOH} / \mathrm{g}$ of oil. It is a comparative measure of rancidity in terms of free fatty acids which are generally formed during decomposition of oil glycerides. AV of GPRV rice oil was $21.4 \pm 2.7 \mathrm{mg} \mathrm{KOH} / \mathrm{g}$ of oil. The saponification value $(\mathrm{SV})$ of the GPRV found to be $202.13 \pm 2.5 \mathrm{mg}$ $\mathrm{KOH} / \mathrm{g}$ of oil. This value is slightly higher than the upper limit of the codex standard range (180-195 mg KOH/g). High saponification values in $\mathrm{KH}$ and $\mathrm{KW}$ have the potentials to use in the industries. The shorter the carbon chain, the more acid is liberated per gram of fat hydrolyzed (low SV). Hence it is considered as a measure of the average molecular weight (chain length) of all the fatty acids present. Peroxide value (PV) is used as an indicator of deterioration of oil. Recommended peroxide value should be lower than 10 meq $\mathrm{O}_{2} / \mathrm{kg}$ for fresh oils and be lower than 40 meq $\mathrm{O}_{2} / \mathrm{kg}$ for crude oil [27]. PV of the GPRV was $18.6 \pm 1.1 \mathrm{meq} \mathrm{O}_{2} / \mathrm{kg}$. Presence of low PV can be further explained in terms of their high antioxidant properties.

\section{CONCLUSION}

In conclusion, agronomic characters were evaluated and these parameters are taken into account when this newly found red pericarp rice variety is selected for the commercial cultivation. The weight of 100 seeds of GPRV was $3.02 \mathrm{~g}$. The seed length of GPRV was $8.0 \mathrm{~mm}$ and the seed width was $3.2 \mathrm{~mm}$. Basic nutritional values of GPRV were evaluated comparing with popular traditional rice varieties of Sri Lanka such as KaluHeenati, Pokkali and Kahawanu. Crude protein content, crude fat content, crude fiber content and ash content of GPRV was $12.0 \pm 0.1 \%$, $2.6 \pm 0.4 \%, 1.5 \pm 0.1 \%$, and $2.0 \pm 0.03 \%$ respectively. The total carbohydrate content of GPRV was $75.9 \pm 0.1 \%$. The calorie value was $375.0 \mathrm{Kcal} / 100 \mathrm{~g}$. Therefore, GPRV provides a nutritionally complete healthy food which is rich in good, unsaturated fatty acids and minerals compared to improved rice varieties in Sri Lanka as well as in other Asian countries. More specifically, protein requirement can be easily meet by consuming this novel GPRV due its high protein content $(12.0 \pm 0.1 \%)$ Benefits of consuming this type of plant proteins can be emphasized as lowering blood pressure and risk of type 2 diabetes. Moreover, high fiber content of this GPRV (1.5 $\pm 0.1 \%$ ) leads to several health benefits such as reducing gastrointestinal disorders and avoiding constipation. GPRV is a good solution as a diet with high $\mathrm{Zn}$ content for people having zinc deficiency because of the comparatively high amount of $\mathrm{Zn}$ content. According to the fatty acid profile, the most prominent fatty acids are palmitic (16:0) and oleic (18:1n-9) presented in this GPRV. Oleic acid is the highest abundant fatty acid $(63.55 \%)$ which is considered as an essential fatty acid required for human growth and development. Hence, this novel red pericarp GPRV is a good source of USFA which 
leads to decrease the intake of saturated fatty acids, in order to reduce cardiovascular disease risk. These primary data can be utilized when this GPRV is screened for further studies.

\section{ACKNOWLEDGMENT}

This work was supported by University of Sri Jayewardenepura under the research grant ASP/01/RE/SCI/2017/54

\section{REFERENCES}

[1] Bhattacharjee, P., R.S. Singhal, and P.R. Kulkarni, Basmati rice: a review. International journal of food science \& technology, 2002. 37(1): p. 1-12.

[2] Priyangani, E., et al., Characterization of Suwandal and Heenati rice varieties for the fragrance gene using Polymerase Chain Reaction based molecular markers. Faculty of Agriculture and plantation management, Wayamba University of Sri Lanka, 2008.

[3] Schenker, S., An overview of the role of rice in the UK diet. Nutrition Bulletin, 2012. 37(4): p. 309-323.

[4] Kariyawasam, T., et al., Proximate composition, calorie content and heavy metals (As, Cd, Pb) of selected Sri Lankan traditional rice (Oryza sativa L.) varieties. Procedia food science, 2016. 6: p. 253-256.

[5] Kariyawasam, T., et al., Effect of parboiling on minerals and heavy metals of selected Sri Lankan traditional rice varieties grown under organic farming. Tropical Agricultural Research and Extension, 2016. 19(1): p. 168172.

[6] Goddard, M.S., G. Young, and R. Marcus, The effect of amylose content on insulin and glucose responses to ingested rice. The American journal of clinical nutrition, 1984. 39(3): p. 388-392.

[7] Juliano, B.O. and M.S. Goddard, Cause of varietal difference in insulin and glucose responses to ingested rice. Plant Foods for Human Nutrition, 1986. 36(1): p. 35-41.

[8] Pathiraje, P., et al., The effect of rice variety and parboiling on in vivo glycemic response. 2010.

[9] Pirasath, S., et al., Effect of dietary curries on the glycaemic index. Ceylon Medical Journal, 2010. 55(4).

[10] Ranawana, D., et al., Glycaemic index of some commercially available rice and rice products in Great Britain. International journal of food sciences and nutrition, 2009. 60(sup4): p. 99-110.

[11] Hettiarachchi, P., et al., Glycaemic indices of different varieties of rice grown in Sri Lanka. Ceylon Medical Journal, 2014. 46(1).

[12] Abeysekera, W., et al., Antioxidant properties of some Sri Lankan traditional red rice (Oryza sativa L.). 2011.

[13] Premakumara, G., et al., Antioxidant, anti-amylase and anti-glycation potential of brans of some Sri Lankan traditional and improved rice (Oryza sativa L.) varieties. Journal of cereal science, 2013. 58(3): p. 451-456.
[14] Abeysekera, W., et al., Growth Inhibition and Cytotoxicity in Human Lung and Cervical Cancer Cell Lines and Glutathione S-Transferase Inhibitory Activity of Selected $S$ ri L ankan Traditional Red Rice (O ryza Sativa L.) Brans. Journal of food biochemistry, 2015. 39(5): p. 585-593.

[15] IRRI, Standard evaluation system for rice.The International rice testing program. $3 \mathrm{rd}$ Edition, The International Rice Research Insttute, Los Banos,Philippines, 1998.

[16] Ranawake, A., U. Amarasingha, and N. Dahanayake, Agronomic characters of some traditional rice (Oryza sativa L.) cultivars in Sri Lanka. Journal of the University of Ruhuna, 2013. 1(1).

[17] Fari, M., D. Rajapaksa, and K. Ranaweera, Quality characteristics of noodles made from selected varieties of Sri Lankan rice with different physicochemical characteristics. Journal of the National Science Foundation of Sri Lanka, 2011. 39(1): p. 53-60.

[18] Young, V.R., et al., Protein requirements of man: Comparative nitrogen balance response within the submaintenance-to-maintenance range of intakes of wheat and beef proteins. The Journal of nutrition, 1975. 105(5): p. 534-542.

[19] Elliott, P., et al., Association between protein intake and blood pressure: the INTERMAP Study. Archives of internal medicine, 2006. 166(1): p. 79-87.

[20] Sluijs, I., et al., Dietary intake of total, animal, and vegetable protein and risk of type 2 diabetes in the European Prospective Investigation into Cancer and Nutrition (EPIC)-NL study. Diabetes care, 2010. 33(1): p. 43-48.

[21] Anderson, J.W., et al., Health benefits of dietary fiber. Nutrition reviews, 2009. 67(4): p. 188-205.

[22] Perera, M., et al., Sensory evaluation, proximate analysis and available carbohydrate content of soy flour incorporated cereal based traditional Sri Lankan breakfast foods. International Journal, 2014. 1(4): p. 2311-2476.

[23] Maret, W. and H.H. Sandstead, Zinc requirements and the risks and benefits of zinc supplementation. Journal of Trace Elements in Medicine and Biology, 2006. 20(1): p. 3-18.

[24] Andersen, P.C. and D.W. Gorbet, Influence of year and planting date on fatty acid chemistry of high oleic acid and normal peanut genotypes. Journal of Agricultural and Food Chemistry, 2002. 50(5): p. 1298-1305.

[25] Goffman, F.D., S. Pinson, and C. Bergman, Genetic diversity for lipid content and fatty acid profile in rice bran. Journal of the American Oil Chemists' Society, 2003. 80(5): p. 485-490.

[26] Bulathsinghala, A.T., Utilization of rice bran in food and soap industry. 2008.

[27] Akubugwo, I. and A. Ugbogu, Physicochemical studies on oils from five selected Nigerian plant seeds. Pak. J. Nutr, 2007. 6(1): p. 75-78. 